\title{
Da fisiologia à biopolítica: discursos sobre a deficiência física na legislação brasileira
}

De la fisiología a la biopolítica: discursos sobre la discapacidad física en la legislación brasileña

From physiology to the biopolitics: discourses on the physical disability on Brazilian legislation

\section{Antonio Lucieudo Lourenço Silva}

Universidade Federal do Ceará, Fortaleza, CE, Brasil.

\section{Luciana Lobo Miranda}

Universidade Federal do Ceará, Fortaleza, CE, Brasil.

Idilva Maria Pires Germano

Universidade Federal do Ceará, Fortaleza, CE, Brasil.

\section{Resumo}

Quando se fala em deficiência física é comum se remeter à normalidade e à eficiência para desempenhar uma função. O objetivo deste artigo é investigar a deficiência física como prática discursiva e os possíveis sujeitos, sobretudo os que tiveram lesão medular, que emergem a partir dela. Analisamos excertos da Classificação Internacional de Funcionalidade, Incapacidade e Saúde - CIF, do programa de Benefício de Prestação Continuada - BPC e do artigo 93 da Lei ${ }^{\circ}$ 8.213/91- Lei de Cotas. Nossa análise fundamenta-se em Michel Foucault, sobretudo nos conceitos de práticas discursivas, biopoder, biopolítica e governamentalidade. Observamos tanto a afirmação legal de um sujeito de direitos, como também de um sujeito que só é reconhecido conforme comprovação de sua deficiência. Em ambas há a prevalência dos critérios biomédicos. Embora estas legislações proponham rediscutir as deficiências, as práticas normativas e reguladoras analisadas legitimam saberes hegemônicos, determinam poderes e produzem subjetividade, tornando-se, muitas vezes, uma inclusão excludente.

Palavras-chave: Pessoas com deficiência, Lesão Medular, Leis, Classificação Internacional de Funcionalidade, Incapacidade e Saúde. 


\title{
Resumen
}

Cuando se trata de la discapacidad es común referirse a la cuestión de la normalidad y eficiencia para realizar una función. El objetivo de este trabajo es reflexionar sobre la discapacidad física como una práctica discursiva y las subjetividades posibles, como aquellos que tienen lesiones de medula espinal, se desprenden de ella. Hacemos uso de los análisis de algunos fragmentos y declaraciones de la Clasificación Internacional del Funcionamiento, la Discapacidad y la Salud - CIF, le programa de beneficios continuo - BPC y el artículo 93 de la Ley $\mathrm{N}^{\circ}$ 8.213/91, conocida como la Ley de Cuotas. Nuestro análisis se basa en Michel Foucault, destacando las prácticas y discursos, y los conceptos de biopoder, la biopolítica y gubernamentalidad. Vemos una afirmación del sujeto jurídico de derechos, sino también a un sujeto que sólo se reconocerá de acuerdo con la evidencia de que es discapacitado. En ambas condiciones, la prevalencia de los criterios biomédicos se impone. Llegamos a la conclusión que a pesar de las legislaciones proponer revisar las discapacidades, las prácticas normativas y reglamentarias analizadas legitiman conocimientos hegemónicos, determinan poderes, y producen subjetividades, y a menudo muestran una inclusión exclusiva.

Palabras-clave: Personas con Discapacidad, Lesión en la Medula Espinal, Leyes, Clasificación Internacional del Funcionamiento, Discapacidad y Salud.

\begin{abstract}
When it comes to disability, it is common to evoke the question of normality and efficiency to perform a function. The aim of this paper is to reflect on physical disability as a discursive practice and the possible subjects that emerge from it, especially those who had spinal cord injury. We analyzed excerpts of the International Classification of Functioning, Disability and Health (ICF), the Benefício de Prestação Continuada -BCP (a program that guarantees a monthly minimum wage for the disabled and the elderly unable to provide for themselves or be provided by their families) and the article 93 of Brazilian Law 8213/91 (which reserves vacancies in the labor market for the disabled). Our analysis is based on Michel Foucault, especially on the concepts of discourse as practices, biopower, biopolitics and governmentality. We find both an affirmation of a legal subject of rights but also a subject who will only be recognized according to the evidence of who is disabled. In both conditions, there is a prevalence of biomedical criteria. Although these laws intend to redefine the disabilities, the normative and regulatory practices analyzed legitimate hegemonic knowledge, determine powers and shape subjectivities, often producing an exclusionary inclusion.
\end{abstract}


Keywords: disabled persons; spinal cord injury; laws; International Classification of Functioning, Disability and Health.

\section{Corpos sem eficiência?}

Ao tratarmos do corpo e seus "desvios" em relação ao discurso da normalidade, estamos interessados em elucidar a produção discursiva da deficiência, especialmente no contexto da legislação e das classificações que lidam sobre o assunto. Tendo por fundamentação Foucault (1997, 2004), interessa-nos problematizar como a nomeação e a classificação da deficiência física envolvem redes de saber, poder e verdade que participam da construção de sujeitos ditos deficientes, como aqueles que apresentam lesão medular.

Sassaki (2003) nos instiga com a provocação que intitula seu texto: "Como chamar as pessoas que têm deficiência?". Não questionamos os termos sobre a deficiência ou o deficiente físico em si, nem pretendemos fazer-lhes uma genealogia. O que questionamos é como esses termos e definições constituem discursos que se efetivam em práticas e vice-versa, atuando na constituição dos sujeitos "deficientes".

"A deficiência como coisa não existe" (Lobo, 2008, p.21), mas o enunciado como marca no e do corpo é reificado, biopolitizado e tornado justificativa para a construção e a promoção de políticas públicas. Os discursos políticos, médicos, jurídicos que as atravessam constituem suas condições de existência.

O nosso interesse é compreender as deficiências como instituição, conforme orienta Lobo (2008, p.21), assinalando que, ao fazermos isso, estamos tomando-as “[...] em sua historicidade, admitindo que, no mesmo momento em que surgiram certos cuidados com elas, começaram a engendrar-se não só os sentidos que hoje lhe atribuímos, como a preocupação com seus destinos."

Lobo (2008) alerta que não se deve negar a existência de marcas corpóreas que figurem a deficiência, mas deve-se desnaturalizar seu caráter biológico, como se apenas a fisiologia do corpo a abrangesse e a explicasse, e que a história se ausentasse desse processo. A matéria da deficiência existe, mas não significa que seja a própria deficiência, que é forma histórica, objetivação dessa matéria.

A prática discursiva sobre a deficiência física dissemina-se na comunidade, nos institutos de previdência, 
nos enunciados de laudos e pareceres médicos, nas políticas de assistência, inclusão social e acessibilidade. Segundo Foucault, o conceito de prática discursiva refere-se a um: "conjunto de regras anônimas, históricas, sempre determinadas no tempo e no espaço, que definiram, em uma dada época e para uma determinada área social, econômica, geográfica ou linguística, as condições de exercício da função enunciativa." (Foucault, 1997, p. 136). Para Foucault (2004), discurso é prática, é ação. A linguagem não apenas nomeia o mundo, mas o constrói.

Quando as práticas discursivas se referem às pessoas com deficiência física, parece existir a preocupação com nomenclaturas para defini-las com base em conceitos clínicos visando diagnóstico e intervenção terapêutica (Meller \& Tesche, 2007). Assim, quando se trata de pacientes com lesão medular, enunciados como "aleijado", “doente", "quando tinha saúde", "perda", "anormalidade", "aposentado por incapacidade ou invalidez", “paralisia irreversível”, "portador de deficiência" e "paciente incapacitado para atividades laborativas" promovem ações, ajudam a constituir corpos considerados deficientes e produz um sujeito desse discurso, o sujeito deficiente por causa de lesão na medula.

Foucault (2006, 2008) aborda a questão de como as instituições atuam sobre o corpo e as implicações que suas práticas têm sobre a forma como um indivíduo se constitui como um sujeito. Como sugere Sullivan (2005), também apoiado em Foucault, o poder médico circula em instâncias dirigindo-se à produção de certos tipos de corpo governáveis, logo, produtivos, e de um certo tipo de sujeito, um corpo-sujeito lesionado.

Outrossim, destacamos o fato de que rotineiramente são exigidos laudos médicos que comprovem a incapacidade física desses indivíduos, de modo que lhes possam conceder benefícios, auxíliosdoença, passes livres em transportes públicos ou lhes autorizem reabilitação. Há também o recebimento de medicações e outros materiais imprescindíveis, como órteses, cadeiras de rodas, cateteres para esvaziamento vesical. Tais comprovações também são necessárias para o usufruto das cotas de contratação de deficientes em empresas e para a inscrição em concursos públicos.

A deficiência parece, então, exteriorizar-se do discurso médico, biológico, de suas marcas fisiológicas e amparar-se no discurso jurídico, trabalhista e político. Passa a dar nome a leis, a fazer circular poderes e legitimar áreas de atuação, ordenar deliberações, circunscrever formas, modelos e programas para o público deficiente. Tais 
discursos definem subjetividades ao se efetuarem em práticas corroboradas por instâncias de poder e atravessadas por variadas instituições.

Para análise de uma discursividade acerca da deficiência física, mais especificamente àqueles com lesão medular, faremos a princípio uma breve discussão teórica acerca da constituição do corpo-deficiente como objeto da biopolítica. Em seguida, discutiremos alguns procedimentos teóricometodológicos baseados em Foucault (1997, 2004) e as condições de emergência de algumas práticas acerca da deficiência para, enfim, analisar alguns excertos e enunciados da Classificação Internacional de Funcionalidade, Incapacidade e Saúde (doravante CIF), do programa de Benefício de Prestação Continuada (BPC) e do artigo 93 da Lei $n^{\circ} 8.213 / 91$, conhecida como Lei de Cotas.

\section{Da utilidade do corpo ao poder e à política sobre a vida}

No advento do século XX consolida-se a aliança feita entre o discurso médico sobre a preservação do corpo e o discurso liberal da eficiência, este advindo da produção industrial. Com essa premissa, aqueles portadores de algum grau de ineficiência, não apenas "defeito" corpóreo, seriam considerados deficientes.
A essa nova modalidade de ser e de fazer governo, já delineada entre os séculos XVI e XVII, Foucault $(2008,2010 b)$ denomina de razão de Estado (raison d'État), a qual instrumentalizou o Estado liberal e que teve como aparato a economia política.

Segundo Foucault (1988), o poder sobre a vida, o biopoder, passou a se desenvolver a partir do século XVII, com base em dois polos principais: o primeiro compreendeu a anátomo-política do corpo humano, que figurou o corpo como máquina, a fim de controlar e ampliar suas forças para melhor utilizá-lo; o segundo polo, após metade do século XVIII, configurou a biopolítica populacional, que se centrou no corpo como espécie, como suporte dos processos biológicos (natalidade, mortalidade, longevidade, nível de saúde). Tais elementos constituintes foram indispensáveis para o desenvolvimento capitalista.

A biopolítica designa o fato de a vida e seus mecanismos penetrarem 0 domínio dos cálculos, como estratégia de Estado, fazendo com que o poder e o saber sejam agentes transformadores da vida humana. Trata-se do biológico refletindose no campo político, pontua Foucault (1988).

As Constituições e toda a atividade legislativa tiveram sua fundamentação nesse tipo de poder controlador da vida, o que legitima um dispositivo normalizador. 
Trata-se então de um poder que distribui "os vivos em um domínio de valor e utilidade", logo, opera em torno da norma, e que, para tanto, necessita qualificá-los, medi-los, avaliá-los, hierarquizá-los (Foucault, 1988, p. 157).

Conforme sublinha Sullivan (2005), uma pessoa com lesão na medula, por exemplo, tem seu corpo tornado objeto inicialmente do poder médico. Este corpo passa, então, a ser submetido a vários diagnósticos (exames para avaliar o nível e extensão da lesão), classificações (paraplegia, tetraplegia), monitoramento e disciplina (reeducação vésico-intestinal, treino de independência funcional), a fim de torná-lo reconhecível e produtivo, para que a sua utilidade seja aumentada.

\section{Pistas teórico-metodológicas: condições} de emergência de enunciados

Foucault nos apoia com sua indagação: "como apareceu um determinado enunciado, e não outro em seu lugar?” (Foucault, 1997, p. 31). Nosso procedimento de investigação analisa na legislação brasileira, enunciados baseados nesse "jogo de aparecimento e dispersão" da constituição de práticas discursivas sobre a deficiência física, com foco na lesão medular.

Para este tipo de análise e para a formação dos discursos levamos em consideração: 1) as condições históricas de aparecimento; 2) as relações estabelecidas entre instituições, processos econômicos e sociais, comportamentos, técnicas, tipos de classificação; 3) as relações entre instituições, técnicas e formas sociais e subjacentes a elas; 4) as relações discursivas que são exteriores ao próprio discurso, que se desenvolvem enquanto prática (Foucault, 1997).

Como materialidade para a análise, elegemos a CIF (OMS, 2003), o BCP, amparado pela Lei Orgânica da Assistência Social, $n^{\circ} 8742 / 93$, e o artigo 93 da Lei de Cotas, porque todos esses instrumentos legais e classificatórios dizem respeito às pessoas com deficiência física que deles precisam se utilizar.

\section{Das formas legais de "praticar" o discurso da deficiência}

Historicamente, a Política Nacional de Saúde da Pessoa com Deficiência no Brasil está circunscrita numa proposta já antevista no artigo 23 do Capítulo II da Constituição Federal de 1988. Tal determinação esclarece que é de competência da União, unidades federativas e municípios cuidarem da saúde e da assistência públicas, da proteção e garantia das pessoas portadoras de deficiências (Ministério da Saúde, 2006). 
A Constituição, em seus artigos 7, 37 e 203, trata das pessoas portadoras de deficiência, abordando, respectivamente, a proibição de qualquer discriminação quanto a salário e critérios de admissão do trabalhador portador de deficiência; determinando a reserva de percentual de cargos e empregos públicos; a assistência social com vistas à habilitação e a reabilitação, além da promoção da integração à vida comunitária, e a garantia de um salário mínimo de benefício mensal à pessoa portadora de deficiência que comprove não possuir meios de garantir a própria manutenção (Constituição da República Federativa do Brasil, 1988).

A construção dessa política é fruto de ampla participação de representantes de instituições, associações e familiares de deficientes, profissionais e usuários de serviços de saúde e de reabilitação (Coordenadoria Nacional para Integração da Pessoa Portadora de Deficiência, 2005; Ministério da Saúde, 2006). Fundamentase no conceito de deficiência como "toda perda ou anormalidade de uma estrutura ou função psicológica, fisiológica ou anatômica que gere incapacidade para o desempenho de atividade, dentro do padrão considerado normal para o ser humano" (Decreto no. 3298/99).

Na década de 1970, estrutura-se, no Reino Unido, a primeira organização de deficientes com engajamento político, The
Union of the Physically Impaired Against Segregation (UPIAS), que denunciava o efeito da exclusão social na produção da deficiência, o que pode ser considerado um movimento de vanguarda, partindo da resistência a uma definição e competência historicamente solidificadas e advindas do modelo médico.

Em 1981, a Organização das Nações Unidas (ONU) declara o Ano Internacional da Pessoa Deficiente, seguida da divulgação do documento Programa de Ação Mundial para Pessoas com Deficiência, elaborado por um grupo de especialistas e aprovado pela ONU, em 1982 (Ministério da Saúde, 2006).

Nesse período e até a segunda metade da década de 1990, apesar do engajamento político das associações de deficientes, o modelo médico prevalecia para definir as deficiências, como se pode constatar no conceito mencionado no Decreto $n^{\circ}$ 3298/99. No entender de pensadores e pesquisadores do chamado modelo social, o modelo médico contribuiu para a exclusão de grande parcela dessa população, principalmente no cenário brasileiro, cujas condições socioeconômicas já excluíam antes mesmo do diagnóstico (Lobo, 2008; Bampi, Guilhem \& Alves, 2010).

Em contrapartida ao modelo médico, que atribui ao indivíduo a causa primeira da desigualdade social e das 
desvantagens vivenciadas pelos deficientes, emerge o modelo social nos anos 1960, no Reino Unido. Bampi e cols.(2010) afirmam que este modelo localiza a causa na estrutura social, posto que seu pressuposto básico é a compreensão da deficiência em termos das desvantagens individuais dispersas em uma sociedade não ajustada à diversidade e, por isso, responsável pelas desvantagens ambientais.

Para esse modelo, a deficiência é um fenômeno sociológico. Conforme Bampi (2007), destacaram-se nos primórdios das discussões do modelo social pensadores que eram deficientes, dentre os quais, Jenny Morris, pesquisadora feminista, e Michel Oliver, sociólogo com uma tetraplegia decorrente de lesão medular. Para esses pensadores, as dificuldades enfrentadas pelo público deficiente não estariam resolvidas por meio da terapêutica biomédica apenas, mas por meio da luta política, incluindo discussões, participação social, movimentos, associações locais e globais, militância não somente por leis para o "tratamento" e reabilitação dos deficientes, mas por melhoria de acessos a serviços públicos, acessibilidade, programas de reinserção laboral. É, portanto, na tensão, no jogo de forças entre o modelo médico e o modelo social, que emerge a materialidade discursiva aqui analisada, a CIF, o BPC e a Lei de Cotas.

\section{Classificação Internacional de}

Funcionalidade, Incapacidade e Saúde

(CIF).

$$
\text { Como parte do arcabouço }
$$
conceitual do modelo social, proposto pela Organização Mundial de Saúde (OMS), a CIF abrange aspectos mais complexos como a funcionalidade, a atividade, a participação social e os fatores ambientais. Determina ainda que tais aspectos sejam utilizados não somente pelos serviços de saúde, mas também em educação, nas legislações, nos programas, na previdência social, nas políticas públicas, nas práticas clínicas, nas áreas de ensino e de pesquisa (Di Nubila \& Buchalla, 2008; Farias \& Buchalla, 2005; OMS, 2003).

\section{A CIF define "funcionalidade"} como termo que abrange as funções do corpo, atividades e participação; "incapacidade" como termo que engloba deficiências, limitação de atividades diárias ou restrição na participação social ou comunitária (OMS, 2003).

As deficiências estão incluídas na avaliação das funções do corpo e são classificadas com base nos critérios de identificação definidos anteriormente. Quando há uma deficiência, ela pode ser classificada segundo a gravidade, por 
exemplo: deficiência ligeira, moderada, grave ou completa da força muscular de um lado do corpo (OMS, 2003).

A CIF é uma reformulação adotada em 2001, que substitui a Classificação Internacional das Deficiências, Incapacidades e Desvantagens (CIDID) publicada em 1980. A perspectiva da CIDID dispunha de modo linear o processo da "deficiência" voltado ao indivíduo do seguinte modo: Doença - Deficiência Incapacidade - Desvantagem (OMS, 2003).

Desde 1980, na versão da CIDID e mantida na CIF, há a intenção de aplicabilidade dessa classificação com fins de servir como "ferramenta estatística", em estudos da população, "como ferramenta de investigação", ou ainda como uma "ferramenta clínica" para avaliar as aptidões profissionais, a reabilitação e seus resultados. A classificação ainda serve como "ferramenta de política social", no planejamento de sistemas de segurança social, de projetos e no desenvolvimento de políticas; e também como uma "ferramenta pedagógica", na elaboração de "programas educacionais", para aumentar a "conscientização" e na realização de ações sociais (OMS, 2003).

Partindo desses enunciados, podem-se destacar alguns balizadores dos saberes e poderes imbricados que constituem a prática discursiva sobre a deficiência no Brasil. Como ferramenta "clínica", o poder médico aqui ainda se vê presente, posto que é de sua "competência" dizer a "verdade" sobre essa funcionalidade e sobre esse padrão de normalidade, como veremos a seguir.

Analisando a ferramenta "política social", novamente a perspectiva da biopolítica atuante dá-se no todo das medidas e sistemas a serem formulados e propostos para se justificar uma política pública. Também podemos constatar a configuração dessa classificação como um dispositivo, segundo Foucault (1987), levando em consideração a "ferramenta pedagógica", por meio da qual se revela o desempenho das "metodologias educacionais e de conscientização", que tão bem caracterizam as sociedades disciplinares.

Para Rose (1988, p. 31), assim como nossas subjetividades e relacionamentos são governados, as “capacidades pessoais e subjetivas dos cidadãos têm sido incorporadas aos objetivos e aspirações dos poderes públicos". Isso constitui o nexo das estratégias biopolíticas das técnicas administrativas e de regulação.

Não obstante esta tentativa de mudança de abordagem, analisando outros enunciados da CIF, como "funcionalidade', "incapacidade", “desvio", "perda", "competência médica", 
mesmo que dentro de um contexto/modelo aparentemente "novo", o que nos chama atenção é a condição de aparecimento, ou ainda, a variação de um discurso biomédico que não se desfez.

Verificam-se ainda - visto que não foram totalmente excluídas - as condições que fizeram nascer essa nova classificação às quais "paradigmaticamente" se opunha: o corpo fisiologicamente desviante e o valor que lhe normatizava, o corpo destituído de suas funções totais, normais e de utilidade, o corpo alterado e dependente de acessos e acessórios.

Segundo a CIF, as deficiências corresponderiam a "um desvio relativamente ao que é geralmente aceito como estado biomédico normal (padrão) do corpo e das suas funções", e seu diagnóstico deve ser feito "essencialmente por pessoas com competência para avaliar a funcionalidade física e mental, de acordo com esses padrões.” (OMS, 2003, p. 13).

Por meio desses excertos, o poder médico, antes fomentador de um discurso excludente, como critica o modelo social, emerge instituído de sua força ou positividade, tendo em vista que sua "competência" ainda diz uma verdade sobre um corpo-sujeito-deficiente, classifica e expõe ritualmente em seus laudos e diagnósticos as balizas de uma classificação normativa, como esta em análise. É a partir dele que os dispositivos legais têm de assentar seus pressupostos e propósitos.

Lembrando o que ensina Foucault (2004), o que há num discurso pode ser detectado pelo que se exclui dele, pelo que o torna rarefeito ou interdito, além disso, suas condições de existência variam, aparecem, crescem e se distribuem no tempo e na história. Aproximamo-nos também da assertiva de que a produção de discurso nas sociedades é simultaneamente controlada, selecionada, organizada e distribuída por procedimentos que visam erguer seus poderes, emergir como práticas e esquivar-se de sua enunciação material como discurso historicamente produzido.

Sendo assim, o discurso da deficiência parece ter se redistribuído por novos procedimentos (a CIF, o modelo social), novas instituições (organizações de saúde, cientistas biomédicos e sociais, comunidade e organizações políticas) e num momento histórico que advoga a inclusão social, a acessibilidade e a participação social. Porém, a afirmação de que a deficiência deva ser comprovada competentemente, isto é, pelo saber-poder médico de forma exclusiva, é, enfim, alcançada pelas políticas e dispositivos da lei. 


\section{Benefício de Prestação Continuada - BPC}

Como parte da Política Nacional para Pessoas com Deficiência, o Benefício de Prestação Continuada (BPC), realizado no Brasil desde 1993, é uma transferência incondicional de um salário mínimo mensal para idosos ou pessoas com deficiência extremamente pobres. Esse benefício está garantido pela Constituição Federal de 1988, no artigo 203 e assegurado pelos artigos 21 e 22 da Lei Orgânica da Assistência Social, de 1993 (Lei n $\left.{ }^{\circ} 8742 / 93\right)$.

A seção I do capítulo IV dessa lei trata especificamente da "conceituação e da comprovação da deficiência". O parágrafo $2^{\circ}$ do artigo 20 esclarece que, para a concessão deste benefício, "a pessoa portadora de deficiência é aquela incapacitada para a vida independente e para o trabalho". A seguir, o $6^{\circ}$ parágrafo do mesmo artigo expõe que a concessão do benefício está sujeita “a exame médico pericial e laudos realizados pelos serviços de perícia médica do Instituto Nacional do Seguro Social - INSS.” (Lei no 8742/93).

Desde 2009, o BPC já adota a CIF como base para os critérios de definição da pessoa com deficiência e, consequentemente, para os critérios de elegibilidade ao recebimento do citado benefício.
Essa avaliação realizada por médico-peritos do INSS verifica, entre outras coisas, no caso da deficiência física: a aptidão para a atividade laboral, os níveis de dificuldades de locomoção, grau de dificuldade para exercer as atividades da vida diária (tais como higiene pessoal, comer, vestir), a escolaridade, os níveis de controle de funções de excreção, a dependência de cuidados permanentes de profissionais de saúde ou de terceiros. Como o benefício é revisado em periodicidade bienal, na etapa de revisão do BPC, a situação e os níveis de vulnerabilidade sociais são dados obtidos por meio da avaliação social (Barbosa, Diniz \& Santos, 2009; Medeiros, Squinca \& Diniz, 2006).

Nesse processo, assinalam Santos, Diniz e Pereira (2009) que, a partir desses padrões de avaliação, o desafio está em analisar em que medida os saberes biomédicos e sociais sobre a deficiência estão presentes no processo pericial, atentando-se para o fato de que tais saberes têm centralidade na avaliação dos impedimentos corporais como critérios para identificar os deficientes, bem como para eleger aqueles que receberão o benefício.

Como já exposto, o saber-poder médico ritualizado é medida de classificação sobre esse corpo-deficiente e para a construção do sujeito-cidadão- 
deficiente. Foucault (2004) analisou como o saber médico interditou (efeito da exclusão) a palavra do louco. Deve-se entender que a exclusão e a segregação se exerceram também de outro modo, por meio de outras instituições (religião, escola, justiça, sistema penal). A entrada da loucura no campo da medicina fez surgir um novo objeto: o doente mental, circunscrito a classificações e a tratamentos advindos do saber-poder médico. Em nossa análise, a definição e a classificação da deficiência, do grau de desvio, da incapacidade, da anormalidade e da perda de funções ainda são pontos relevantes para decisões judiciárias e políticas, como antes se deu com a loucura.

Não afirmamos que as condições de aparecimento, que os procedimentos de exclusão do discurso do deficiente no decurso da história foram similares aos que fizeram emergir e segregar o discurso do louco. Mas assinalamos que a prática discursiva que se construiu sobre a loucura, como analisou Foucault (1997), nos permite analisar a emergência da deficiência física como medida de eficiência avaliada e classificada por instituições diversas.

Apesar disso, a própria segregação implementada no discurso da deficiência, que se utilizou de termos como "aleijado", "paralítico" ou "incapacitado físico", teve um "respaldo" médico e normativo que lhe diagnosticou, que lhe reformulou seus nomes "cientificamente" (deficiente físico, incapacitado laboral, dependente para realizar atividades), lhe mediu a dependência para realizar atividades (grau da deficiência, medida funcional da independência) e que lhe classificou, tendo em vista as propostas da CIF.

Lembremos mais uma vez Foucault (2004) ao abordar uma forma de excluir um discurso e reafirmá-lo: a vontade de verdade. Esta é regida pela vontade de saber, por meio da qual se cria um discurso verdadeiro, conforme um ritual requerido, por alguém de direito. Ao ser ritualizado, portanto, esse discurso passa a ser enunciado. $\mathrm{O}$ ritual, desse modo, auxilia o controle dos discursos e a produção de sua enunciação, posto que ele qualifica os falantes dessa verdade, define gestos, comportamento, circunstâncias, fixa a eficácia imposta em seus enunciados. Como resume Foucault (2004), os discursos religiosos, judiciários, terapêuticos e políticos estão associados a essa prática.

Nesse aspecto, seguindo nossa análise do BPC, para apoiar, portanto, uma garantia constitucional e legislativa, o poder médico é requerido, sua competência e tutela científica são acionadas; ele é a vontade de verdade, que dimensionará, por meio de ritualizadas definições (perícia, laudos e pareceres), as decisões jurídicas e 
políticas e as garantias sociais. O laudo é a verdade anunciada por meio do qual se enunciará o lugar da lesão, da incapacidade, da deficiência.

Baseando-se nisso, a desvantagem individual presente na versão da CIDID de 1976 se transforma em desvantagem social, aqui entendida como política pública, lei de amparo social, responsabilidade politica do Estado, compensação monetária para a desvantagem física para o trabalho.

Assim, o BPC parece funcionar como medida compensatória para as desvantagens ambientais do Estado e da sociedade. As diferenças e ausências estatais estão "dirimidas" em forma de lei que salvaguarde ao cidadão uma renda, mediante a sua impossibilidade de trabalhar e de contribuir para esse Estado excludente e alheio às desvantagens sociais, muitas vezes preteridas frente às individuais.

Campbell (2005), com base no termo "fícção legal" de Jeremy Bentham, assinala que no caso da deficiência, a ficção reside no fato de que uma orientação biomédica para prescrições e classificações avaliativas da deficiência torna-se pré-requisito para o gerenciamento administrativo eficiente e para a delimitação legal da deficiência. Isto é, uma verdade médica é exigida para corroborar uma política ou medida legal e jurídica, e não as próprias medidas ou políticas são competentes tuteladores dessa verdade.

\section{Lei $n^{\circ}$ 8.213/91 - cotas, inclusão e governamentalidade}

Consoante a essa lei, também referida como Lei de Cotas ou de Reserva Legal de Cargo, o fundamento primeiro das políticas em favor de quaisquer minorias é a criação de salvaguardas (Ministério do Trabalho e Emprego, 2007). Essa medida legal visa estabelecer a obrigatoriedade de as empresas com cem (100) ou mais empregados, preencherem uma parcela de seus cargos com pessoas portadoras de deficiência habilitadas. Esclarece o artigo 89 que a habilitação e a reabilitação profissional e social devem proporcionar ao beneficiário incapacitado para o trabalho e às pessoas portadoras de deficiência os meios para a "reeducação" e "readaptação" profissional e social indicados para participar do mercado de trabalho e do contexto em que vivem (Lei $\left.\mathrm{n}^{\circ} 8.213 / 91\right)$.

Para efeitos de comprovação da "condição de deficiência", faz-se necessário que a pessoa esteja reabilitada, ou seja, que tenha cumprido um programa oficial de recuperação da atividade laboral, o que se deve atestar por "documentos públicos oficiais, expedidos pelo Instituto 
Nacional do Seguro Social (INSS) ou órgãos que exerçam função por ele delegada", além de ter comprovação por meio de laudo médico, emitido por médico do trabalho da empresa ou outro. "O laudo deverá especificar o tipo de deficiência e ter autorização expressa do(a) empregado(a) para utilização do mesmo pela empresa, tornando pública a sua condição" (Ministério do Trabalho e Emprego, 2007, p. 25).

Nesse sentido, não basta um conceito, um nome, uma marca, é necessária a autorização legal para utilizálo, para que, por meio dela, se usufrua o direito à chamada inclusão social. Mais uma vez a comprovação para a inclusão testificada pelo saber-poder médico e sua perícia ritualizada: seu discursoinstituição-verdade.

Isso posto, trazemos outro conceito basilar para nossa reflexão: a governamentalidade. Diferente do que seria governo numa acepção de poder unilateral e assimétrico, o do Estado, a governamentalidade seria o conjunto de "mecanismos e procedimentos destinados [...] a conduzir a conduta dos homens" (Foucault, 2010a, p. 43). Em outras palavras, Foucault (2010a) admite que é impossível governar os homens sem fazer operações da ordem da verdade. E para governá-los, são necessários procedimentos e técnicas que falem do modo como vivem e que lhes dêem uma noção que se amplie e permita o governo dos filhos, governo das almas, governo da casa e de si mesmos. As políticas de inclusão referentes à deficiência, logo, seriam consideradas estratégias de governamentalidade, levando em consideração toda a economia política e o instrumental técnico que as envolvem.

Analisando os enunciados "readaptação", "habilitação" e a formação discursiva da "reabilitação" como meios e estratégias para tornar aptos cidadãos para o trabalho, tocamos a questão da utilidade do corpo para atingir determinada marca de desempenho, de modo a conceder ao indivíduo o direito de ter uma vaga que lhe garanta o benefício.

Pode-se inferir com isso que a vaga não é para todos; ela é específica, distribuída para uma categoria habilitada pedagógica e tecnicamente, uma deficiência eficientemente educada e preparada para as exigências das sociedades democráticas e liberais. Vemos, por outro lado, a questão previdenciária (cotas na lei da previdência) baseada na trabalhista (exigência do Ministério do trabalho): o fato de a incapacidade para o trabalho ser motivo para uma reabilitação que é exigida legalmente. Não é uma habilitação autônoma, mas uma inclusão calculável. 
Somos de acordo com Campbell (2005, p. 126) quando afirma que as estratégias coercitivas de normalização, em crescimento nas sociedades neoliberais, facilitadas pelo uso de regimes legais que visam eliminar ou modificar a "deficiência", fornecem evidências de que essas sociedades estão desenvolvendo em uma forma de eugenia "positiva", mesmo que sob o disfarce da promessa liberal de escolha e liberdade. Para a autora, as ficções legais da deficiência atuam como uma incitação da lógica da neutralidade da "habilidade" dentro de práticas neoliberais de liberdade que tem o efeito de promover a ilusão da inclusão.

No entendimento de Veiga-Neto e Lopes (2007), as políticas de inclusão social funcionam demarcando limites, designações, termos e classificações, reforçando noções de normalidade e anormalidade, disseminando perfis padronizados, assim, "podem estar contribuindo para uma inclusão excludente" (p. 949). Nessa seara, para alguém ser alcançado pelas políticas de inclusão, há de ser primariamente considerado como um excluído socialmente. É primeiro necessário estar dito do lado de fora para estar incluído como possível partícipe. Essa observação dos autores é um ponto fundamental para nossas análises: "a igualdade de acesso não garante a inclusão e, na mesma medida, não afasta a sombra da exclusão" (p. 949), porque atua no âmbito da norma. Esta, por sua vez, funciona como "matriz de inteligibilidade na qual as políticas e as práticas de inclusão fazem sentido e são justificadas" (p.949).

\section{A biopolítica como racionalidade para as políticas sobre deficiências?}

O discurso da deficiência está inserido nas tecnologias de poder da biopolítica. Será por meio do ordenamento de um "novo" discurso sobre os signos do corpo que se poderá engendrar uma política voltada àqueles que necessitam de espaços legitimados para as suas singularidades. Para além das avaliações e gerenciamentos, evidenciados no material analisado, urge um discurso não excludente, nem compensatório, que respeite efetivamente as diferenças e fomente espaços em que elas não sejam apenas aceitas ou incluídas, mas vividas.

Consoante Rose (1988), o Governo, leia-se o Estado democrático liberal, depende da produção de verdades que encarnem as subjetividades dos governados, aquilo que os objetive como algo pensável, calculável e controlável. Percebe-se, então, que o discurso sobre a deficiência é elaborado como política de aceitabilidade, como uma unidade que deve ser assim conduzida pelas instituições 
e saberes-poderes que ao mesmo tempo lhe amparem e lhe constituam.

Não cabe mais interrogar a deficiência como coisa, como uma verdade universal; suas arestas não podem exceder os discursos (médico, político-econômico, neoliberal, previdenciário, jurídico) de sua existência. Está circunscrita a tais instituições; seu discurso é distribuído e reiterado por meio dessas.

Em nosso estudo, apontamos algumas continuidades e rupturas nas práticas discursivas que revelam e se efetuam no contexto do corpo eficiente e da deficiência. A definição da deficiência como perda permanece, os usos de medidas biomédicas nas avaliações mantem-se como dispositivos classificatórios necessários. No entanto, a funcionalidade é deslocada de uma fatalidade (desvantagem individual) para um interesse social e político (desvantagem social). Tais efeitos e práticas são retomados e reafirmados em programas e políticas de Estado. Há uma racionalidade biopolítica subjacente, ou ainda, circunjacente à construção dessa prática discursiva.

Como alerta Campbell (2005), a contínua reiteração da lei sobre a "corporeidade defeituosa", por meio da designação de categorias legais como "deficiência" ou pessoa deficiente", parece impedir aos sujeitos deficientes qualquer possibilidade de fuga das práticas normalizadoras de compensação.

As estratégias de inclusão social abrem espaço para as assertivas da exclusão, a qual parece ocultada em nome da igualdade e da autonomia dos sujeitos, do distanciamento do Estado quanto aos serviços especializados.

Dessa forma, entendemos que os sujeitos-deficientes, ainda que possam ou desejem recusar uma posição de passividade ante as denominações legais, os diagnósticos e classificações médicas, necessitam de tais medidas legais e seus desdobramentos para usufruírem de direitos a que, em tese, fazem jus e por eles devem lutar.

Este é o modus operandi requerido para a autorregulação estatal, que Foucault (2008) afirmou ser necessário para o bom funcionamento de nossas sociedades ocidentais, normalizadoras, controladoras e avaliadoras da eficiência. A biopolítica atua configurada em estratégias impessoais - mas elaboradas como "igualitárias" - e legitima um desempenho a ser alcançado por todos os corpos-cidadãos, principalmente os destoantes.

Compartilhando da afirmação de Campbell (2005), as pessoas com deficiência confrontam desafios diários de discriminação velada quando negociam a sua existência em um mundo que lhes 
apaga o valor. Para além dos cálculos e das cotas, há subjetividades em formação.

Não é nosso interesse destituir as políticas públicas, as atuais classificações e dispositivos legais de seu alcance e de sua relevância pública. Visamos, entretanto, enveredar pelos processos e dinâmicas que constituíram e constituem as deficiências como medidas de valor, de utilidade, de diagnóstico e de classificação para configurar e instituir políticas, justificar direitos e definir outras práticas.

Ainda que as novas classificações e legislações proponham rediscutir e repensar as deficiências, torna-se imprescindível abordar o fato de que a prática de categorização, normativa, reguladora, como afirmou Foucault (1997, 2004) e com base no que foi aqui explicitado, legitima saberes, determina poderes, evidencia verdades e produz subjetividades.

Resultante disso, podemos observar a afirmação legal de um sujeito de direitos e de cidadania, mas, ao mesmo passo, a afirmação de um sujeito que só será reconhecido conforme comprovação de que é deficiente, como analisado nos dispositivos legais. Em ambas as condições, a prevalência dos critérios biomédicos se impõe. A diferença em si não é condição para direitos, a não ser se ela estiver fundamentada na ordem do discurso da deficiência como enunciado ou verdade médico-legal.

Diante do exposto, cabe-nos admitir que tais práticas são necessários pontos de inflexão e reflexão para se compreender como as subjetividades dos "deficientes físicos", circunscritas e relacionadas diretamente a esses espaçosefeitos, são reconstruídas e transformadas.

\section{Referências}

Bampi, L.N.S. (2007). Percepção de qualidade de vida de pessoas com lesão medular traumática: uma forma de estudar a experiência da deficiência. Tese de doutorado. Doutorado em Ciências da Saúde, Universidade de Brasília, Brasília, DF.

Bampi, L.N.S; Guilhem, D. \& Alves, E. D. (2010). Modelo social: uma nova abordagem para o tema deficiência. Rev. Latino-Am. Enfermagem [online]. 18(4). Disponível em http://www.scielo.br/pdf/rlae/v18n4/ pt 22.pdf

Barbosa, L., Diniz, D. \& Santos, W. (2009). Diversidade corporal e perícia médica: novos contornos da deficiência para o Benefício de Prestação Continuada. Revista Textos \& Contextos. Porto Alegre, v.8, n.2 p. 377-390. Disponível em 
http://revistaseletronicas.pucrs.br/ojs/

index.php/fass/article/view/6351/465

$\underline{0}$

Campbell, F. K. (2005). Legislating disability: negative ontologies and the government of legal identities. In: Tremain, S. Foucault and the Government of Disability. The University of Michigan Press.

Constituição da República Federativa do Brasil. (1988, 5 de outubro). Disponível em http://www.planalto.gov.br/ccivil_03 /constituicao/constitui\%C3\%A7ao.ht $\underline{\mathrm{m}}$

Coordenadoria Nacional para Integração da Pessoa Portadora de Deficiência (2005). Acessibilidade. Brasília: Secretaria Especial dos Direitos Humanos. Decreto n. 3298. (1999, 20 de dezembro). Regulamenta a política nacional para a integração da pessoa portadora de deficiência, consolida as normas de proteção e dá outras providências. Brasília, DF: Presidência da República. Disponível em

http://portal.mec.gov.br/seesp/arquiv os/pdf/dec3298.pdf

Di Nubila, H. B. D. V. \& Buchalla, C. M. (2008). O papel das Classificações da OMS - CID e CIF nas definições de deficiência e incapacidade. Rev Bras Epidemiol 2008; 11(2): 324-35.
Disponível em http://www.scielo.br/pdf/rbepid/v11n 2/14.pdf

Farias, N. \& Buchalla, C. M. (2005). A classificação internacional de funcionalidade, incapacidade e saúde da Organização Mundial de Saúde: conceitos, usos e perspectivas. Rev. Bras. Epidemiol, 8 (2), 187-193. Disponível em http://www.scielo.br/pdf/rbepid/v8n2 111.pdf

Foucault, M. (1997). A arqueologia do saber. (5a ed.). Rio de Janeiro: Forense Universitária.

Foucault, M. (2004). A ordem do discurso: aula inaugural no Collège de France, pronunciada em 2 de dezembro de 1970. (L. F. A., Sampaio. Trad.). São Paulo: Edições Loyola.

Foucault, M. (2006). A hermenêutica do sujeito. (2a ed.). São Paulo: Martins Fontes.

Foucault, M. (1988). Direito de morte e poder sobre a vida. Em: Foucault, M. História da sexualidade 1: a vontade de saber. (18a ed.). Rio de Janeiro: Graal.

Foucault, M. (2010a). Do governo dos vivos. Curso no Collège De France, 1979-1980 (excertos). São Paulo: CCS-SP.

Foucault, M. (2008). Segurança, território, população: curso dado no Collège de 
France (1977-1978). São Paulo:

Martins Fontes.

Foucault, M. (2010b). The birth of biopolitics: lectures at the Collège de France (1978-1979). New York: Picador, 2010.

Foucault, M. (1987). Vigiar e punir: nascimento da prisão. Petrópolis: Vozes.

Lei n. 8.742, de 07 de dezembro de 1993. (1993, 7 de dezembro). Dispõe sobre a Lei Orgânica da Assistência Social. Diário Oficial da União. Disponível em

http://www.planalto.gov.br/ccivil_03 /Leis/L8742.htm

Lei n. 8.213 de 24 de julho de 1991. (1991, 24 de julho). Dispõe sobre os Planos de Benefícios da Previdência Social e dá outras providências. Diário Oficial da União. Disponível em

http://www.planalto.gov.br/ccivil_0 3/Leis/L8213cons.htm

Lobo, L. F. (2008). Os infames da história: pobres, escravos e deficientes no Brasil. Rio de Janeiro: Lamparina.

Medeiros, M., Diniz, D. \& Squinca, F. (2006). Estudo do Programa Brasileiro de Transferências de Renda para a População com Deficiência e suas famílias no Brasil: uma análise do Benefício de Prestação Continuada. Texto para discussão $\mathrm{n}^{\circ}$ 1184. Brasília: IPEA. Disponível em http://www.ipea.gov.br/Destaques/B $\underline{\text { PC_Relatorio_TDIpea_Medeiros_Di }}$ niz_Squinca.pdf

Meller, V. A. \& Tesche, L. (2007). Vivências corporais de pessoas com deficiência física. Visão Global, Joaçaba, v. 10, n. 1, p. 61-84, jan./jun. Disponível em http://editora.unoesc.edu.br/index.ph p/visaoglobal/article/view/476/221

Ministério da Saúde. (2006). Manual de legislação em saúde da pessoa com deficiência. (2a ed.) Brasília: Editora do Ministério da Saúde. Disponível em

http://bvsms.saude.gov.br/bvs/public acoes/legislacao_deficiencia.pdf

Ministério do Trabalho e Emprego (2007). A inclusão de pessoas com deficiência no mercado de trabalho. (2a ed.) Brasília: Secretaria de Inspeção do Trabalho. Disponível em http://www.mte.gov.br/fisca trab/inc lusao_pessoas_defi12_07.pdf

Organização Mundial de Saúde (2003). Classificação Internacional de Funcionalidade, Incapacidade $e$ Saúde: Classificação Detalhada com definições. 217p. Disponível em http://www.periciamedicadf.com.br/c if2/cif_portugues.pdf 
Rose, N. (1988). Governando a alma: a formação do eu privado. Em: Silva, T. T. (org.). Liberdades reguladas. Petrópolis: Vozes, p.30-45.

Santos, W., Diniz, D. \& Pereira, N. (2009). Deficiência e perícia médica: os contornos do corpo. Reciis, v. 3, n. 2, p.16-23. Disponível em http://www.reciis.cict.fiocruz.br/inde x.php/reciis/article/viewFile/264/295

Sassaki, R. K. (2003). Como chamar as pessoas com deficiência? In:

Vida independente: história, movimento liderança, conceito, filosofia e fundamentos. São Paulo: RNR, p. 12-16.

Sullivan, M. (2005). Subjected bodies: paraplegia, rehabilitation, and the politics of movement. In: Tremain, S. Foucault and the Government of Disability. The University of Michigan Press.

Veiga-Neto, A. \& Lopes, M. C. (2007). Inclusão e governamentalidade. Educ. Soc., Campinas, vol. 28, n. 100 - Especial, p. 947-963. Disponível em

http://www.scielo.br/pdf/es/v28n100/ a1528100.pdf. do Ceará, na linha de pesquisa Cultura e subjetividades contemporâneas, com a dissertação com título provisório de (Trans)formação de subjetividades após lesão medular: hermenêutica de novos sujeitos.

E-mail: lucieudo@hotmail.com

Luciana Lobo Miranda. Doutora em Psicologia pela PUC-Rio. Professora do programa de pós-graduação em Psicologia da Universidade Federal do Ceará, vinculada à linha de pesquisa Cultura e subjetividades contemporâneas. É membro do Laboratório de Psicologia em Subjetividade e Sociedade (LAPSUS).

E-mail: lobo.lu@uol.com.br

Idilva Maria Pires Germano. Doutora em Sociologia pela Universidade Federal do Ceará. Atualmente é Professora Associada da Universidade Federal do Ceará, no Programa de Pós-Graduação em Psicologia, na linha de pesquisa Cultura e subjetividades contemporâneas, e no curso de Graduação em Psicologia. É membro do Laboratório de Psicologia em Subjetividade e Sociedade (LAPSUS). E-mail: idilvapg@ufc.br

Antonio Lucieudo Lourenço Silva. Atua na área de reabilitação com sujeitos acometidos de lesão medular. Mestrando em Psicologia pela Universidade Federal 